\title{
Steady and Unsteady Fireline Intensity of Spreading Fires at Laboratory Scale
}

\author{
Paul-Antoine Santoni*, Frédéric Morandini and Toussaint Barboni
}

SPE UMR 6134 CNRS - University of Corsica, Campus Grimaldi BP 52, 20250 Corte, France

\begin{abstract}
Fireline intensity is the rate of heat release per unit time and per unit length of a fire front. With rate of spread, it is one of the most relevant quantities used in forest fire science. It allows to evaluate the effects of fuel treatment on fire behavior, to establish limits for prescribed burning or to support fire suppression activities. Although it is widely used, conversely its measurement is often coarse and has received very little attention. Furthermore, literature only refers to steady state when dealing with this quantity. In the present paper, we measure directly the fireline intensity at laboratory scale by using the oxygen consumption calorimetry principle. This methodology allows us to provide this quantity not only for steady fires but also for unsteady spreading fires for the first time. We show that the current approach used to assess fireline intensity can lead to overestimation from about $20 \%$. As the experiments were conducted under wellventilated conditions, the heat release rate calculated by calorimetry was compared to mass loss rate and heat of combustion taking into account the combustion efficiency.
\end{abstract}

Keywords: Fireline intensity, unsteady fire spread, oxygen consumption calorimetry.

\section{INTRODUCTION}

Fires devastate regularly forests and shrublands as well as populated areas all over the world. Foresters and fire fighters are faced with problems such as the management of wildland/urban interfaces, the establishment of safety zones and suppression strategies. To deal with such situations, the fire phenomenon and specially the combustion of vegetation need to be better understood. The ability of the forest fire community in modeling and simulating forest fire spread [14], as well as developing management approaches and techniques [5], has increased significantly in recent years. Modeling has become an essential tool in forest fire research and is now a crucial instrument in the studies of risk mapping [5], fire propagation [1-4], as well as in forest management $[1,4]$. However, the precision of wildland fire assessment tools is limited by the understanding of many key variables. Heat release rate (HRR) of a fuel is among the most important parameter for understanding combustion process, fire characteristics and propagation rates. It serves for instance to define flame geometry and temperature fields for open fires [6]. This parameter has been studied recently in both attempts to classify vegetation as a fuel for forest fires and to understand the role of transport in porous fuels beds [7]. This last study provided some calorimetry data relevant to issues associated with wildland fuel characterization. The experimental apparatus used was a bench scale calorimeter allowing measuring the combustion of small samples.

In the present work, we propose to investigate the HRR of spreading fire by using a Large Scale Heat Release Rate Calorimeter (LSHR) at laboratory scale. More precisely we

*Address correspondence to this author at the University of Corsica, Campus Grimaldi BP 52, 20250 Corte, France; Tel: 0033 495450161; Fax: 00 33 495450162; E-mail: santoni@univ-corse.fr; santoni.paulu@wanadoo.fr deal with the fireline intensity which is with rate of spread, one of the most relevant quantities used in forest fire science. Although the experiments at field scale [8] are valuable to validate the numerical models of fire spread, they are not appropriated to study precisely the combustion of forest fuels. Experiments at laboratory scale allow focusing on accurate phenomena as the fire parameters are monitored and controlled more easily.

The concept of fireline intensity was introduced by George Byram [9] in the 50's. Frontal fire intensity synonymous with Byram's fireline intensity is the rate of heat release per unit time per unit length of the active flaming zone of the fire front. It is given by:

$I_{B}=H w r$

where $I_{B}(\mathrm{~kW} / \mathrm{m})$ is the fireline intensity, $H(\mathrm{~kJ} / \mathrm{kg})$ is the heat yield of the fuel, $w\left(\mathrm{~kg} / \mathrm{m}^{2}\right)$ is the weight of the fuel consumed in the active flame front and $r(\mathrm{~m} / \mathrm{s})$ is the rate of spread of the fire. Fireline intensity is a widely used measure in forest fire science: it helps to evaluate the effects of fuel treatment on fire behavior [10], to establish limits for prescribed burning [11] and to assess fire impacts on ecosystems [12]. It is also used as an indicator for the classification of community in terms of risk [13] and as a quantitative basis to support fire suppression activities $[14,15]$. However in that case caution should be taken since results obtained for a specific fuel type cannot be generalized to different fuel structure [16]. Although fireline intensity is widely used in fire science as detailed here above, conversely very limited effort has concentrated on its measurement, which is often coarse. And literature only refers to steady state when dealing with this quantity. The reason of the little use of fireline intensity by modelers may to be found in the difficulty encountered to measure this information accurately. Because it is in general obtained from estimates of available fuel energy per unit area of ground and fire spread rate, little is known 
about how well these computed intensities represent actual rates of energy release. However, this quantity contains in itself the most part of the physics involved in a spreading fire. It is with rate of spread and fire front shape the most meaningful information for the test and validation of all types of models of fire spread, from empirical to physical [3] and detailed models [1].

In the present paper, we measure directly the fireline intensity at laboratory scale by using the oxygen consumption calorimetry principle. This methodology allows us to provide this quantity not only for steady fires but also for unsteady spreading fires for the first time. We show that the classical approach (see Eq. 1) used to assess fireline intensity can lead to overestimation from about $20 \%$. As the experiments were conducted under well-ventilated conditions, the heat release rate calculated by calorimetry was compared to mass loss rate and heat of combustion taking into account the combustion efficiency.

\section{METHOD AND MATERIALS}

\subsection{Measuring Heat Release Rate by Oxygen Consump- tion Calorimetry}

HRR which describes the fire size of burning materials is a fundamental parameter that is essential to estimate fire hazards and design fire protection systems [17]. Regarding its use in forest fire science, it should be recalled that HRR and the derived quantities like fireline intensity $(\mathrm{kW} / \mathrm{m})$ and reaction intensity $\left(\mathrm{kW} / \mathrm{m}^{2}\right)$ are used to model the heat source in some fire spread modeling approach [18]. The usual practice of measuring the rate of heat release in experimental fires is based on the oxygen consumption (OC) principal [19] which states that heat release is proportional to oxygen consumed for complete combustion of most organic com- pounds. Huggett [20] showed that the heat released per unit mass of consumed oxygen is approximately $13.1 \mathrm{MJ}$. This principle is applied extensively at bench-scale and in largescale fire tests [17].

HRR measurements based on OC calorimetry were conducted using the newly installed 1 MW LSHR calorimeter (3 $\mathrm{m} \times 3 \mathrm{~m}$ hood) at the University of Corsica. Although this calorimeter has a maximum capacity of $1 \mathrm{MW}$, it is typically used for fires less than $500 \mathrm{~kW}$ to prevent flames from entering the duct. Fig. (1) shows the Open-burning HHR Calorimeter with a combustion bench inside.

This experimental arrangement is categorized in the Furniture Calorimeters group [17]. The mass loss rate is measured and the exhaust gases are analyzed for composition, temperature, optical obscuration and flow speed with a bidirectional probe. The heat release rate calculation uses representative values of measured quantities at the sampling position in the exhaust duct. The exhaust duct flow profile is essential to the accuracy of the oxygen consumption calorimetry measurement. In order to validate the whole installation and reduce the measurement uncertainty a calibration procedure with a propane burner is required. Because the calculation of heat release rate requires a large number of individual measurements, it is essential to have an independent confirmation of measurement accuracy. This calibration is accomplished by burning an accurately measured flow of gas having a well-defined heat of combustion. A burner and flow system configured for propane gas were used that can produce flows corresponding to a range of heat release rates, from $10 \mathrm{~kW}$ to over $300 \mathrm{~kW}$. Due to the HRR expected for the vegetative fuel bed used in this study, the calibration of the LSHR hood and ducting was conducted burning propane gas at different increments corresponding to levels of $40 \mathrm{~kW}$

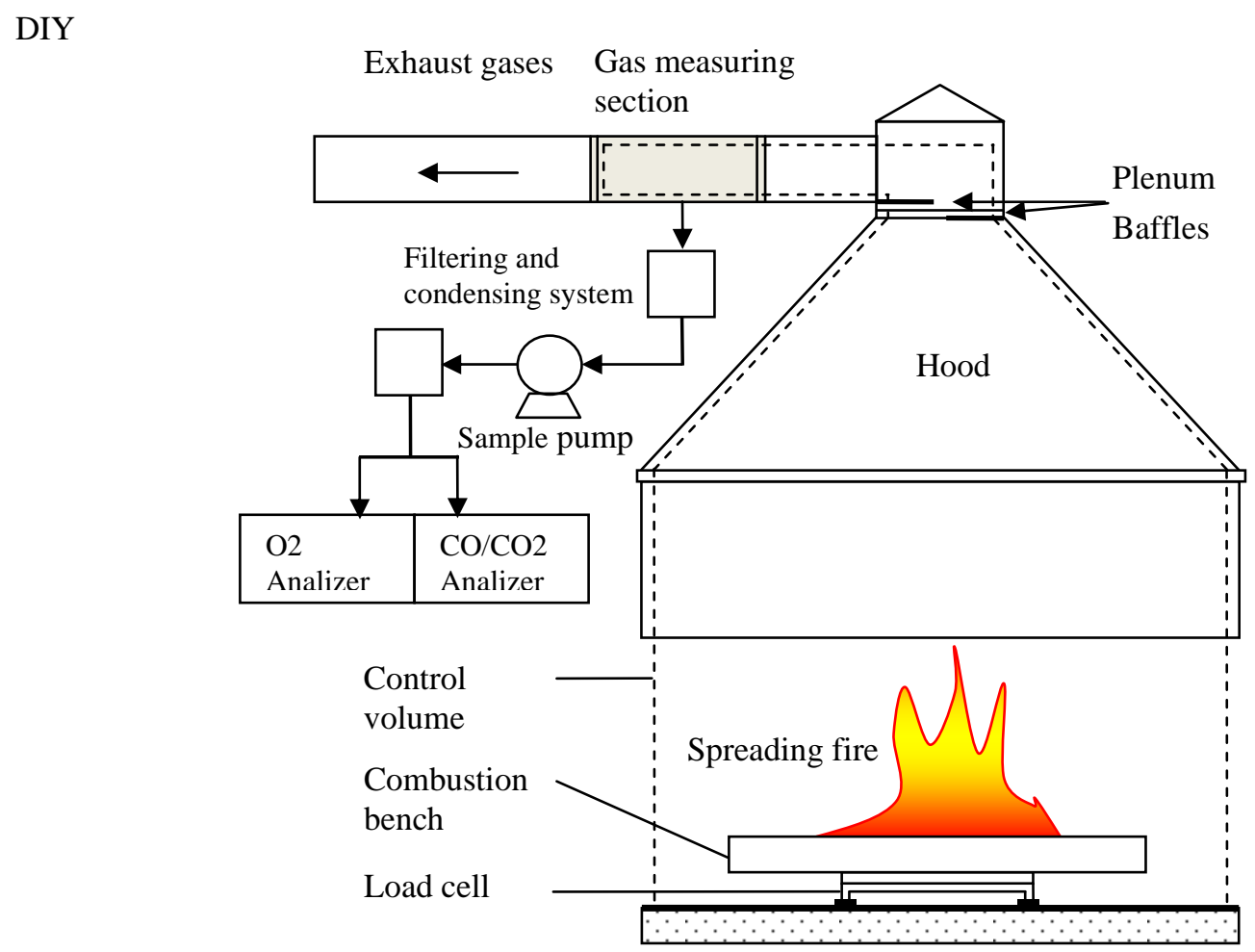

Fig. (1). Schematic of the open fire test combustion system. 
$-100 \mathrm{~kW}-40 \mathrm{~kW}$. A comparison factor was determined from the ratio of the oxygen calorimetry and burner heat release rates. It is used as a validation and quality control factor for the calorimetry. The relative agreement between the oxygen calorimetry and the burner output was better than 0.97 for the entire range of heat release rates considered.

According to Thornton's rule, HRR can be calculated from the measured oxygen mass consumption rate. Different formulations were derived depending on the method used to determine the mass consumption (volumetric flow rate [21] or mass flow rate [22]) and depending also on the measurement devices available for gas analysis [22]. We recall here the formulation derived by Parker [21], for which the main simplifying assumptions are: the amount of energy released by complete combustion per unit mass of oxygen consumed is taken constant; all gases are considered to behave as ideal gases; the analyzed air is defined by its composition in $\mathrm{O}_{2}$, $\mathrm{CO}_{2}, \mathrm{H}_{2} \mathrm{O}$ and $\mathrm{N}_{2}$; all other gases are lumped into $\mathrm{N}_{2}$. HRR can be calculated from the oxygen molar flow rate,

$\dot{q}=E\left(\dot{n}_{\mathrm{O}_{2}}^{\circ}-\dot{n}_{\mathrm{O}_{2}}\right) W_{\mathrm{O}_{2}}$

where $\dot{q}$ is the HRR, $E$ is the energy released per mass unit of $\mathrm{O}_{2}$ consumed for the combustion of the test sample, $\dot{n}_{\mathrm{O}_{2}}^{\circ}$ and $\dot{n}_{\mathrm{O}_{2}}$ represent respectively the molar flow rates of $\mathrm{O}_{2}$ in incoming air and in the exhaust duct and $W_{\mathrm{O}_{2}}$ is the molecular weight of oxygen.

The volume flow rate of incoming air, referred to standard conditions is given by:

$\dot{V}_{a}=\frac{\dot{n}_{O_{2}}^{\circ}}{X_{O_{2}}^{\circ}} \frac{W_{a i r}}{\rho_{0}}$

where $\mathrm{X}_{\mathrm{O}_{2}}^{\circ}$ is the molar fraction of $\mathrm{O}_{2}$ in incoming air and $W_{\text {air }}$ is the molecular weight of dry air at $25^{\circ} \mathrm{C}$ and $1 \mathrm{~atm}$. The oxygen depletion factor is introduced for convenience. It is given by

$\phi=\frac{\dot{n}_{O_{2}}^{\circ}-\dot{n}_{O_{2}}}{\dot{n}_{O_{2}}^{\circ}}$

Combining Eqs 2-4, one obtains:

$\dot{q}=\frac{E \rho_{0} W_{O_{2}}}{W_{\text {air }}} X_{O_{2}}^{\circ} \phi \dot{V}_{a}$

It should be mentioned that gases are measured on dry basis. Water vapor is removed because the analyzers cannot handle wet mixtures. Thus the mole fraction of gases in air is derived from the analyzers' measurement and from air humidity. For instance the mole fraction of oxygen in air is given by

$X_{\mathrm{O}_{2}}=\left(1-X_{\mathrm{H}_{2} \mathrm{O}}\right) X_{\mathrm{O}_{2}}^{a}$

where superscript $a$ denotes the mole fraction in the analyzers. Unfortunately, in an open system, not the incoming air flow rate $\dot{V}_{a}$ but the flow rate in the exhaust duct $\dot{V}_{s}$ is measured. A relationship between $\dot{V}_{a}$ and $\dot{V}_{s}$ is obtained and after some development (not given here), the HRR is given by the three following relations:

$$
\begin{aligned}
& \dot{q}=\frac{E \rho_{0} W_{O_{2}}}{W_{\text {air }}}\left(1-X_{\mathrm{H}_{2} \mathrm{O}}^{\circ}\right) X_{O_{2}}^{a^{\circ}} \dot{V}_{s, 298}\left[\frac{\phi}{(1-\phi)+1.105 \phi}\right] \\
& \dot{V}_{s, 298}=22.4 A \frac{k_{t}}{k_{p}} \sqrt{\frac{\Delta P}{T_{S}}} \\
& \phi=\frac{X_{O_{2}}^{a^{\circ}}\left(1-X_{\mathrm{CO}_{2}}^{a}\right)-X_{\mathrm{O}_{2}}^{a}\left(1-X_{\mathrm{CO}_{2}}^{a^{\circ}}\right)}{X_{\mathrm{O}_{2}}^{a^{\circ}}\left(1-X_{\mathrm{CO}_{2}}^{a}-X_{O_{2}}^{a}\right)}
\end{aligned}
$$

where $X$ denotes the molar fraction, $W_{\text {air }}$ and $\rho_{0}$ are respectively the molecular weight and the density of dry air at $298 \mathrm{~K}$ and 1 atm. $\dot{V}_{s, 298}$ is the standard flow rate in the exhaust duct. The superscript ${ }^{\circ}$ is for the incoming air. $A$ is the cross sectional area of the duct, $k_{t}$ is a constant determined via the propane burner calibration, $k_{p}=1.108$ for a bi-directional probe, $\Delta p$ is the pressure drop across the bi-directional probe and $T_{S}$ is the gas temperature in the duct.

\subsection{Measuring Fireline Intensity by Oxygen Consump- tion Calorimetry}

Experimental fires were conducted under no slope and no wind for line-ignition fires on a combustion table located inside the LSHR hood. The basic layout is presented in Fig. (2). The table is an air-entrained concrete plate of $2 \mathrm{~m}$ long and $2 \mathrm{~m}$ wide, placed on a load cell in order to measure the mass loss over time during the test fire.

Three species of vegetation were considered in these test fires: Pinus pinaster needles, Avena fatua straw (wild oats), and Genista salzmannii spines (an endemic broom). The fuel was scattered uniformly on the tray to obtain homogeneous bed. The bed of fuel occupies only the central part of the tray. To ensure fast and linear ignition, a small amount of alcohol and a flame torch were used. Different fuel loads with different moisture content on dry basis were considered (4-7\%). Different sizes of fuel bed were used $(0.9 \mathrm{~m} \times 1.1 \mathrm{~m}$, $1 \mathrm{~m} \times 1.5 \mathrm{~m}$ and $1 \mathrm{~m} \times 2 \mathrm{~m})$. The heat release rate was measured during the spreading across the fuel beds using the set of equations given in the previous section. The fireline intensity obtained by oxygen consumption calorimetry denoted $I_{O C}$ hereafter, corresponds directly to the measured HRR for fire front of $1 \mathrm{~m}$ width. For fuel bed of smaller width $W$, the fireline intensity is given by:

$I_{O C}=\dot{q} / W$

The fire fronts remained quasi linear during the whole spreads and exhibited a weak curvature on the flanks when reaching the end of the combustion bench. The range of fuel bed properties for each species considered in this study are provided in Table 1 where $w, \delta, \rho, \sigma$ and $\beta$ represent respectively the fuel load, the depth of the fuel bed, the density of the particles, the surface to volume ratio of the particles and the packing ratio of the fuel bed. The net heat of combustion 


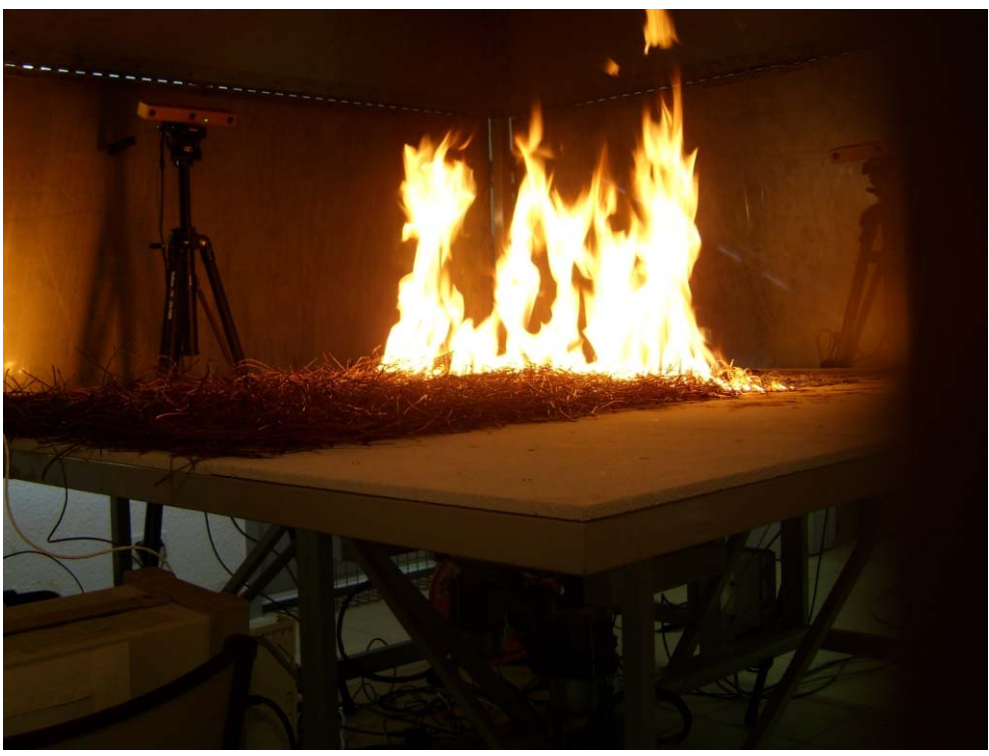

Fig. (2). Linear spreading for a $1 \mathrm{~m} \times 1.5 \mathrm{~m}$ bed of Pinus Pinaster needles.

Table 1. Test Materials

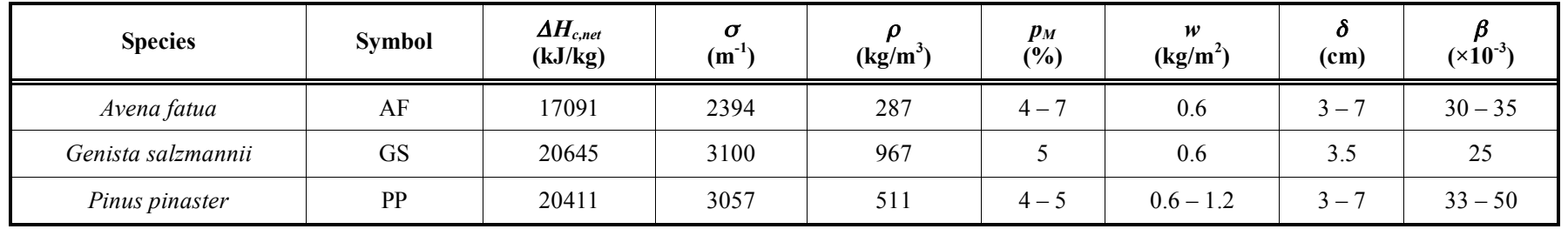

$\Delta H_{c, \text { net }}$ values were derived from the gross heat of combustion values $\Delta H_{c, \text { gross }}$ measured in an oxygen bomb calorimetry. The surface to volume ratio and density were measured following the methodology proposed by Moro [23]. The moisture content was determined by drying the species in an oven at $60{ }^{\circ} \mathrm{C}$ for 24 hours. The fuel bed height was measured in each test leading to the porosity of the fuel bed $\beta=w /(\rho \delta)$. The ambient temperature and relative humidity ranged respectively from $18{ }^{\circ} \mathrm{C}$ to $21{ }^{\circ} \mathrm{C}$ and from $35 \%$ to $49 \%$ for the whole tests.

\section{RESULTS AND DISCUSSION}

\subsection{Energy Constants Estimated for the Three Vegeta- tion Species}

When estimating the HRR of a reaction from the chemical species concentration, the main hypothesis lays on the knowledge of the evolution of the combustion gases during the reaction. When detailed chemistry of the material of interest is unknown, Huggett's value $\left(E=13.1 \mathrm{MJ} / \mathrm{kg}\right.$ of $\left.\mathrm{O}_{2}\right)$ is used [20]. If the fuel composition is known, the energy constants can be estimated. In our case, the combustion of the vegetation species was represented by the stoichiometric combustion of a chemical compound $\mathrm{C}_{x} \mathrm{H}_{y} \mathrm{O}_{z}$, given by:

$$
\begin{aligned}
& \mathrm{C}_{x} \mathrm{H}_{y} \mathrm{O}_{z}+\left(x+\frac{y}{4}-\frac{z}{2}\right)\left(\mathrm{O}_{2}+3.76 N_{2}\right) \rightarrow \\
& x \mathrm{CO}_{2}+\frac{y}{2} \mathrm{H}_{2} \mathrm{O}+3.76\left(x+\frac{y}{4}-\frac{z}{2}\right) N_{2}
\end{aligned}
$$

where $x, y$ and $z$ are obtained from an ultimate analysis of CHON for the three species considered (Table 2). The energy constants were estimated, using the following expression:

$E_{s t}=\frac{\Delta H_{c, \text { net }} M_{\text {fuel }}}{\left(x+\frac{y}{4}-\frac{z}{2}\right) M_{O_{2}}}$

where $M_{\text {fuel }}$ and $M_{O 2}$ represent respectively the molecular weight of fuel and $\mathrm{O}_{2}$. Energy constants obtained through this calculation are given in Table $\mathbf{2}$ for the different fuels. There are referred to as stoichiometric energy constants.

We can see that the values of $E_{s t}$ are greater than Huggett's average for the three vegetation species considered in this study. The deviation ranges from $3 \%$ to $10 \%$, respectively for GS and PP. The average energy constant of the three fuels is equal to 13.95 giving a mean deviation of about $6 \%$ with Huggett's average.

\subsection{Steady Fireline Intensity of Spreading Fires}

It should be pointed out that fireline intensity was defined for steady state condition (Eq. 1) and was mainly used [9-15] in such condition up to now. In this section we will investigate whether Eq. 1 is an accurate formulation to assess fireline intensity for quasi-steady spreading fires. The results will be reported in term of HRR. Indeed, for most of the experiments the fuel bed was $1 \mathrm{~m}$ width and the fire front remained quasi-linear during the spreading. Hence HRR is synonymous with fireline intensity for those cases. For 
Table 2. Ultimate Analysis and Energy Constants Estimated

\begin{tabular}{|c|c|c|c|c|c|}
\hline Species & Symbol & $\begin{array}{c}\boldsymbol{x} \\
(\mathbf{m o l})\end{array}$ & $\begin{array}{c}\boldsymbol{y} \\
(\mathbf{m o l})\end{array}$ & $\begin{array}{c}\boldsymbol{z} \\
(\mathbf{m o l})\end{array}$ & 2.77 \\
\hline \hline Avena fatua & AF & 3.66 & 5.74 & 2.37 & 14.39 \\
\hline Genista salzmannii & GS & 4.26 & 6.72 & 2.32 & 13.48 \\
\hline Pinus pinaster & PP & 4.15 & 6.65 & 2.51 & 13.98 \\
\hline
\end{tabular}

smaller width of fire front, HRR results are provided and fireline intensity calculated with Eq. 10 is discussed. Achieving a steady state for a spreading fire depends on different conditions. Among these are: the fuel load, the fuel moisture content and the length of the fuel bed. Although the present paper does not focus on the condition to reach a steady state, some results will first be presented in order to show the influence of the former parameters on the fire behavior. Fig. (3) displays some examples of the HRR curves obtained for fires spreading across AF for a fuel load of $0.6 \mathrm{~kg} / \mathrm{m}^{2}$. It should be mentioned that the sampling rate was $1 \mathrm{~Hz}$ for all experiments conducted in this work except for that corresponding to the dotted curves in Fig. (3) for which it was 3 Hz. The fuel bed was $0.9 \mathrm{~m}$ width and $1.1 \mathrm{~m}$ long for each run. The moisture content on dry basis was $4 \%$ for the oven dried fuel and $7 \%$ for the wet fuel. For the oven dried straw, the drying was performed in an oven at $60^{\circ} \mathrm{C}$ for 24 hours. Since it re-hydrated during its removal from the oven and the positioning on the bench of combustion and the ignition, a sample was loaded to evaluate the fuel moisture content before the run. The height of the fuel bed was less than $6 \mathrm{~cm}$ for the compact fuel bed and about $7 \mathrm{~cm}$ for the other fuel beds leading to packing ratios respectively of more than 0.035 for the compact fuel and less than 0.03 for the others. For the three tests provided here, the mean fireline intensities calculated with Eq. 10 were $62 \mathrm{~kW}, 47 \mathrm{~kW}$ and $31 \mathrm{~kW}$ during the steady stage. The mean rates of spread were respectively $0.86 \mathrm{~cm} / \mathrm{s}, 0.65 \mathrm{~cm} / \mathrm{s}$ and $0.52 \mathrm{~cm} / \mathrm{s}$. We can see on Fig. (3) that the influence of moisture content and packing ratio on fireline intensity is very important. We noticed that a

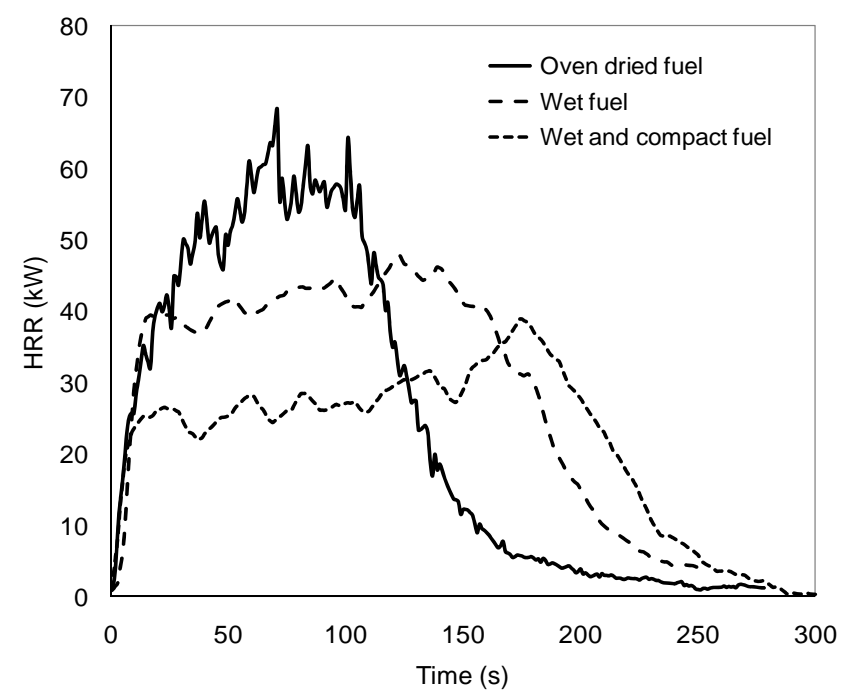

Fig. (3). Heat release rates for fire spread across fuel beds $(0.9 \mathrm{~m} \times$ $1 \mathrm{~m}$ ) of $A F$ for a load of $0.6 \mathrm{~kg} / \mathrm{m}^{2}$ and different fuel conditions on moisture content and packing ratios. quasi-steady state was achieved more or less quickly in function of the moisture content. The drier the fuel load, the highest was the rate of spread and the latest the steady state was reached. Although the packing ratio influences drastically the intensity, conversely it had no impact on the establishment of the steady state. A slight increase on fireline intensity was observed at the end of some experiments. This increase was attributed to a vortex induced at the end of the combustion bench by the air extractors. The vortex enhances the combustion by increasing the mixing between combustible gases and air. This phenomenon was mainly observed for the experiments with a rate of spread lower than $0.5 \mathrm{~cm} / \mathrm{s}$.

Fig. (4) shows two curves of HRR obtained for fires spreading across PP for two loads: $0.6 \mathrm{~kg} / \mathrm{m}^{2}$ and $1.2 \mathrm{~kg} / \mathrm{m}^{2}$. The fuel bed was $1.0 \mathrm{~m}$ width and $1.5 \mathrm{~m}$ long for each run. The fuel was oven dried at $60^{\circ} \mathrm{C}$ for 24 hours and the moisture content on dry basis was $5 \%$ for both loads. The height of the fuel bed was $3.5 \mathrm{~cm}$ and $5 \mathrm{~cm}$ respectively for the fuel loads of $0.6 \mathrm{~kg} / \mathrm{m}^{2}$ and $1.2 \mathrm{~kg} / \mathrm{m}^{2}$. Their packing ratios were respectively 0.034 and 0.047 . We observed that a quasisteady state is quickly reached for the lighter load while the spreading remains unsteady for the heavier one. Experiments were performed with a longer fuel bed $(1.0 \mathrm{~m}$ width $\times 2 \mathrm{~m}$ long) in order to investigate whether a steady state could be reached for a load of $1.2 \mathrm{~kg} / \mathrm{m}^{2}$. Fig. (5) displays a HRR curve obtained for this configuration with the corresponding mass loss over time superimposed on the HRR.

We noticed that the steady state is reached for this longer fuel bed. The higher the fuel load, the latest the steady state is reached and depending on the length of the bed the steady state might be visible or not. For the fuel load of $0.6 \mathrm{~kg} / \mathrm{m}^{2}$ and for the experiment with a fuel load of $1.2 \mathrm{~kg} / \mathrm{m}^{2}$ provided in Fig. (5), we further observed that constant rates of spread and constant rates of mass loss were obtained during the time interval corresponding to a quasi-steady HRR. Fig. (5) depicts the mass loss which is linear for this time interval. For both tests, the mean rates of spread were $0.34 \mathrm{~cm} / \mathrm{s}$ and $0.4 \mathrm{~cm} / \mathrm{s}$, the mean rates of mass loss were $-2.05 \mathrm{~g} / \mathrm{s}$ and $-5.06 \mathrm{~g} / \mathrm{s}$ and the mean fireline intensities were $34 \mathrm{~kW}$ and $79 \mathrm{~kW}$ respectively for $0.6 \mathrm{~kg} / \mathrm{m}^{2}$ and $1.2 \mathrm{~kg} / \mathrm{m}^{2}$ loads. The intensity is more than doubled for a double load. This increase in intensity is partly due to an increase in rate of spread but mostly due to an increase in mass loss rate.

Figs. (3-5) clearly shows that even for zero wind and no slope fire, achieving a steady state at laboratory scale requires some attention. The methodology adopted in the present work guaranties that a sound steady state in energy release is obtained that corresponds effectively to constant rate of mass loss and constant rate of spread. We are thus able to test whether Eq. 1 is an accurate formulation to assess fireline intensity for quasi-steady spreading fires. In this equation, $H$ 


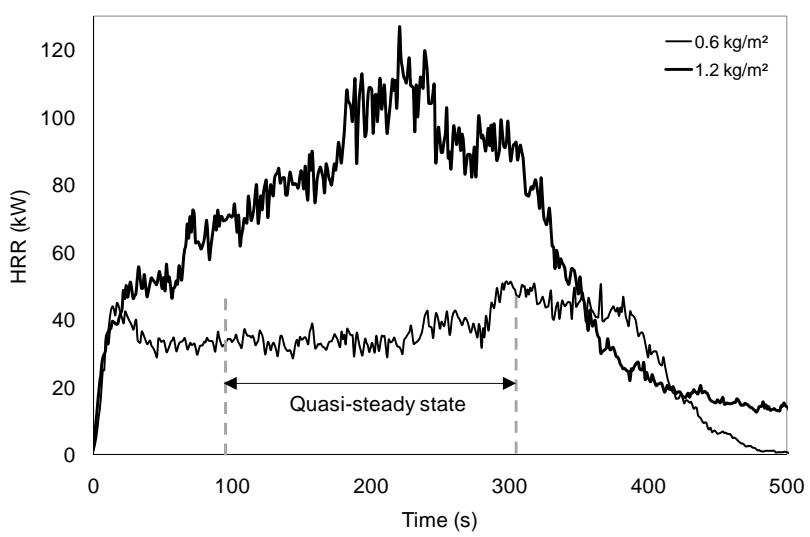

Fig. (4). Heat release rates for fire spread across fuel beds $(1 \mathrm{~m} \times$ $1.5 \mathrm{~m})$ of $P P$ needles for loads of $0.6 \mathrm{~kg} / \mathrm{m}^{2}$ and $1.2 \mathrm{~kg} / \mathrm{m}^{2}$.

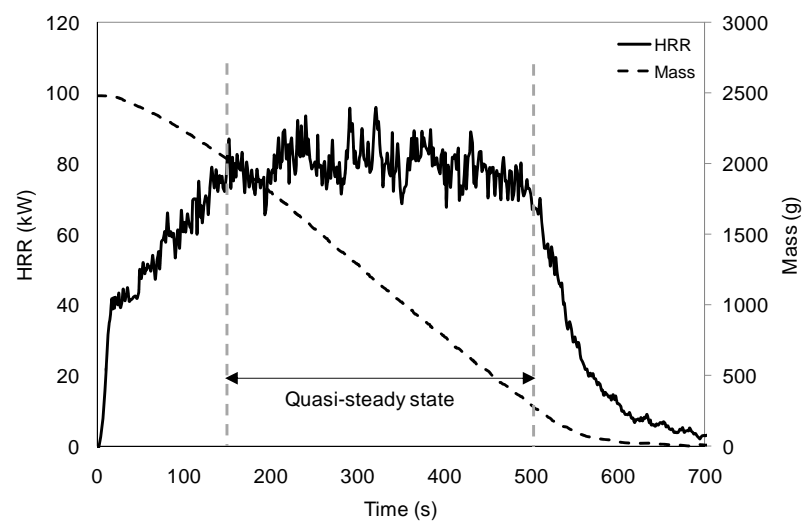

Fig. (5). Heat release rate for fire spread across a fuel bed $(1 \mathrm{~m} \times 2$ $\mathrm{m})$ of $P P$ needles with a load of $1.2 \mathrm{~kg} / \mathrm{m}^{2}$.

is the heat yield which is obtained from the net (or low) heat of combustion value $\Delta H_{c, n e t}$, adapted to the fuel moisture content:

$H=\Delta H_{c, n e t}-L_{M} \times p_{M}$

where $L_{M}(24 \mathrm{~kJ} / \mathrm{kg}$, [9]) is the heat required to separate the bound water from the fuel and to vaporize the water in the fuel and $p_{M}$ is the moisture content percentage point based on dry fuel. The value of the net heat of combustion is derived from the high (or gross) heat of combustion value $\Delta H_{c, \text { gross }}$ to take into account the latent heat absorbed when the water of reaction is vaporized. It is given by:
$\Delta H_{c, \text { net }}=\Delta H_{c, \text { gross }}-L_{V} \times m_{H_{2} \mathrm{O}}$

where $L_{V}=2257 \mathrm{~kJ} / \mathrm{kg}$ is the latent heat of vaporization of water and $m_{\mathrm{H}_{2} \mathrm{O}}$ is the mass of water released during the combustion of one $\mathrm{kg}$ of fuel. The $\Delta H_{c, g r o s s}$ is determined from measurement in an oxygen bomb calorimeter.

Averaged fireline intensities calculated with Eq. 1 (Byram's formulation) and Eq. 10 (OC measurements) are provided in Table 3 for the species considered. At least three repetitions were carried out for each load. We can see that Byram's formulation, $I_{B}$ overestimates the fireline intensity measured by $\mathrm{OC}, I_{O C}$. The ratio between both formulation given by a linear regression performed on the whole set of data is $I_{O C} / I_{B} \approx 0.77$. This ratio is given by fuel beds in Table 3 for the different species and loads. We note that the values range from 0.72 to 0.82 .

Two reasons may explain the difference between Byram's formulation and OC results. The first one is due to the methodology adopted to apply Byram's formulation. As mentioned previously, the fire fronts remained quasi linear during the whole spreads but exhibited a weak curvature on the flanks. This shape leads to a slight overestimation of the burned area when the fire reaches the end of the combustion bench. The second one is due to combustion efficiency that is overestimated in Byram's formulation. Indeed, Eq. 1 considered the heat yield $H$ (Eq. 13) while the combustion is incomplete. In order to support this remark, the combustion efficiency $\chi$ was calculated for all runs (see Table 3 ). $\chi$ is the ratio between the effective heat of combustion $H_{\text {eff }}$ and the heat yield, $\chi=H_{\text {eff }} / H$. $H_{\text {eff }}$ was determined for each test, by dividing the total heat released by the total mass lost during the quasi-steady stage. Values of combustion efficiency obtained in this study are in agreement with those provided by other investigators for free burn test [24]. An improvement of Byram's formulation for the measurement of fireline intensity may be obtained by taking into account combustion efficiency in Eq. 1, leading to the following equation:

$I_{B M}=\chi H w r$

\subsection{Unsteady Fireline Intensity of Spreading Fires}

According to the previous results Eq. 1 fails to represent accurately the averaged fireline intensities measured during quasi-steady fires. In the present section we propose another

Table 3. Overall Data of Burning Tests

\begin{tabular}{|c|c|c|c|c|}
\hline Species & $\begin{array}{c}A F \\
\left(0.6 \mathrm{~kg} / \mathrm{m}^{2}\right)\end{array}$ & $\begin{array}{c}G S \\
\left(0.6 \mathrm{~kg} / \mathrm{m}^{2}\right)\end{array}$ & $\begin{array}{c}P P \\
\left(0.6 \mathrm{~kg} / \mathrm{m}^{2}\right)\end{array}$ & $\begin{array}{c}P P \\
\left(1.2 \mathrm{~kg} / \mathrm{m}^{2}\right)\end{array}$ \\
\hline$I_{O C}$ & 53,3 & 27,8 & 33,9 & 86,8 \\
\hline$I_{B}$ & 74 & 36,8 & 43,5 & 105,2 \\
\hline$I_{O C} / I_{B}$ & 0.72 & 0.76 & 0.78 & 0.82 \\
\hline$\chi$ & 0.81 & 0.85 & 0.88 & 0.84 \\
\hline$H_{e f f}(\mathrm{~kJ} / \mathrm{kg})$ & 13052 & 16650 & 17051 & 16271 \\
\hline
\end{tabular}


formulation to evaluate fireline intensity based on the mass burning rate.

$$
I_{S}=\left(\dot{m}_{\text {fuel }} \chi H\right) / W
$$

where $\dot{m}_{\text {fuel }}$ is the mass loss rate of the fuel. Based on the combustion efficiency obtained previously, $\chi$ this formulation is obviously suitable for averaged quantities under steady state condition. It will thus be tested in the following against time-varying quantities. To this end, fluctuating and unsteady fireline intensities will be considered through three different cases. The first case concerns a quasi-steady fire spreading across a fuel bed of PP with a load of $0.6 \mathrm{~kg} / \mathrm{m}^{2}$ for which the fireline intensity has exhibited some fluctuations but remained roughly around a constant value. The second and third cases are unsteady fires spreading respectively across fuel beds of AF with a load of $0.6 \mathrm{~kg} / \mathrm{m}^{2}$ and PP with a load of $1.2 \mathrm{~kg} / \mathrm{m}^{2}$. Fig. (6) shows the results obtained for the first case. The rate of mass loss was filtered with a moving average in order to avoid overshoots. We can see that the energy release rate calculated with Eq. 16 matches well the HRR measured by OC calorimetry. The large fluctuations of the HRR are accurately reproduced over time. However, the finest fluctuations could obviously not be reconstructed. There are beyond the possibility of the experimental setup used to record the mass loss. However, we can notice that the increase of HHR at the beginning of the fire as well as the decrease at the end of the test is depicted by Eq. 16 .

Figs. (7 and 8) correspond to the test of Eq. 16 in the case of fires that present unsteady behavior. As depicted in both figures, this relation is able to represent the general tendencies of the fireline intensities over time. Not only the large fluctuation but also the drastic increases and peak of HHR are well modeled for both species and fuel loads considered. Here also, the decrease in HRR at the end of the test is depicted. Byram's formulation (Eq. 1) could obviously not been applied to measure the fire power for such cases. Conversly Eq. 16 seems appropriate to perform such measurements. Extending this formulation to field tests for which OC calorimetry is not appropriate due to the scale of the experiments is thus promising, provided that the fire front resem-

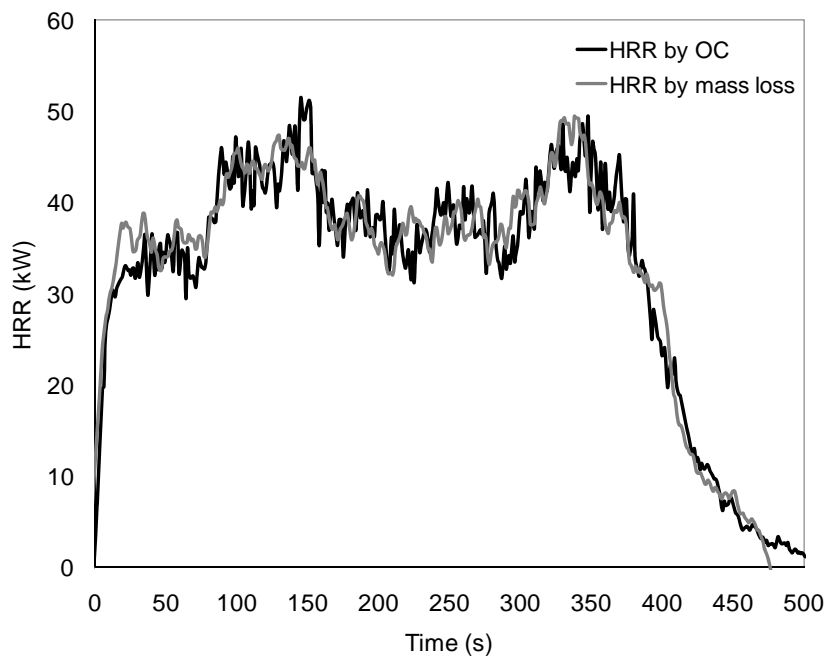

Fig. (6). Fluctuations of a fireline intensity for a fire spreading across a fuel bed $(1 \mathrm{~m} \times 1.5 \mathrm{~m})$ of $P P$ with a load of $0.6 \mathrm{~kg} / \mathrm{m}^{2}$.

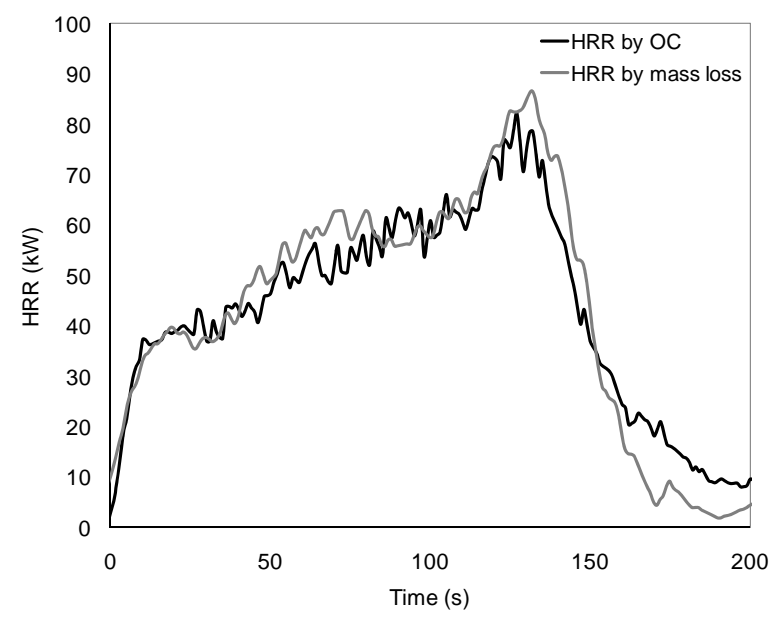

Fig. (7). Unsteady fireline intensity for a fire spreading across a fuel bed $(1 \mathrm{~m} \times 1 \mathrm{~m})$ of $A F$ with a load of $0.6 \mathrm{~kg} / \mathrm{m}^{2}$.

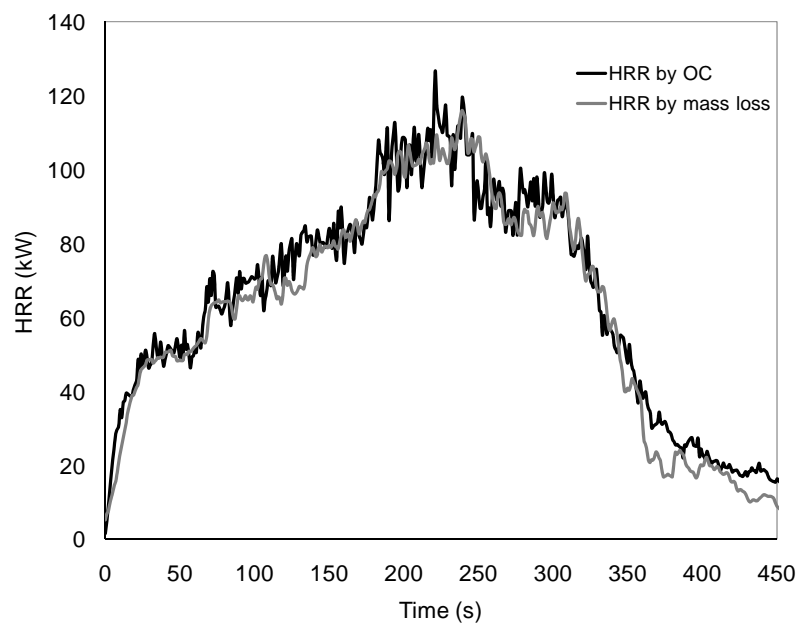

Fig. (8). Unsteady fireline intensity for a fire spreading across a fuel bed $(1 \mathrm{~m} \times 1.5 \mathrm{~m})$ of $P P$ with a load of $1.2 \mathrm{~kg} / \mathrm{m}^{2}$.

bles a two-dimensional panel moving through the vegetation. Our results demonstrate that using the complete heat yield $H$ is not appropriate. In a free burn test the fuel is burned with unlimited access to air, but some of the volatiles do not burn completely, leaving for example $\mathrm{CO}$, soot and unburnt hydrocarbons, containing further potential energy. Therefore $H_{\text {eff }}=\chi H$ is lower than $H$.

\section{CONCLUSIONS}

The measurement of fireline intensity was poorely adressed up to now and literature only refers to Byram's formulation to measure the fire power. This paper clearly shows that this formulation present some limitation for steady fires while it is commonly accepted that it is useless for unsteady fires. Oxygen consumption calorimetry allowed us measuring fireline intensity and to our knwoledge, it is the first time that steady and unsteady fireline intensities are explicitely measured for spreading fires. This methodology also demonstrates that actual combustion processes vary considerably from out-of-context laboratory estimates, for example heat of combustion determinations using oxygen bomb calorimetry rather than oxygen depletion calorimetry during free burning. These results are of importance for modelers that have 
to face with little information available on the source terms useful for forest fire modeling. In this paper, we also investigated an alternative formulation based on the measurement of burning rate to assess fireline intensity. As the experiments were conducted under well-ventilated conditions, the heat release rate calculated by calorimetry can be used to evaluate a formulation based on mass loss rate and heat of combustion provided that combustion efficiency is taken into account.This approach lead us to reproduce accuretaly the main tendency of the HRR of a spreading fire. The large fluctuation of energy release rate for steady fires, as well as the envelope of the energy release rate for unstady fires were provided. Testing this formulation at field scale is the necessary next step of the present work.

\section{ACKNOWLEDGEMENTS}

This work was carried out in the scope of project PROTERINA-C supported by the EU under the Thematic 3 of the Operational Program Italia/France Maritime 2007-2013, contract: G25I08000120007.

\section{REFERENCES}

[1] W. E. Mell, M. A. Jenkins, J. Gould, and P. Cheney, "A physics based approach to modeling grassland fires", Int. J. Wildland Fire, vol. 16, pp. 1-22, 2007.

[2] X. Zhou, S. Mahalingam, and D. Weise, "Experimental study and large eddy simulation of effect of terrain slope on marginal burning in shrub fuel beds", Proc. Combust. Inst., vol. 31, pp. 2547-2555, 2007.

[3] J. H. Balbi, J. L. Rossi, T. Marcelli, and P. A. Santoni, "A 3D physical real-time model of surface fires across fuel beds", Combust. Sci. Technol., vol. 179, pp. 2511-2537, 2007.

[4] D. Morvan, S. Meradji, and G. Accary, "Physical modelling of fire spread in grasslands", Fire Saf. J., vol. 44, pp. 50-61, 2008.

[5] P. Fiorucci, F. Gaetani, and R. Minciardi, "Development and application of a system for dynamic wildfire risk assessment in Italy", Environ. Model. Soft., vol. 23, pp. 690-702, 2008.

[6] Babrauskas, V., Peacock, R.D. "HRR. The single most important variable in fire hazard", Fire Saf. J., vol. 18, pp. 255-292, 1992.

[7] P. Bartoli, A. Simeoni, H. Biteau, J. L. Torero, and P. A. Santoni, "Determination of the main parameters influencing forest fuel combustion dynamics", in press doi:10.1016/j.firesaf.2010.05.002

[8] P. A. Santoni, A. Simeoni, J. L. Rossi, F. Bosseur, F. Morandini, X. Silvani, J. H. Balbi, L. Rossi and D. Cancelieri, "Instrumentation of wildland fire: Characterisation of a fire spreading through a Mediterranean shrub", Fire Saf. J., vol. 41, pp. 171-184, 2006.

[9] G. M. Byram, "Combustion of forest fuels", in Forest fire: control and use, K. P. Davis, Ed. New York: Mc Graw-Hill, 1959, pp. 6189.

[10] J. A. Fites, and C. Henson, "Real-time evaluation of effects of fueltreatments and other previous land management activities on fire behavior during wildfires", Report of the Joint fires science rapid response project, US Forest Service, 2004, pp 1-13.

[11] A. G. McAthur, "Control burning in eucalypt forests", Comm. Australia. Forestry and Timber Bureau. Leaflet, No 80, 1962.

[12] K. A. Hammil, and R. A. Bradstock, "Remote sensing of fire severity in Blue Mountains: influence of vegetation type and inferring fire intensity", Int. J. Wildland Fire, vol. 15, pp. 213-226, 2006.

[13] M. De Luis, M. J. Baeza, J. Raventos, and J. C. Gonzales-Hidalgo, "Fuel characteristics and fire behaviour in mature Mediterranean gorse shrubland", Int. J. Wildland Fire, vol. 13, pp. 79-87, 2004.

[14] M. E. Alexander, and W. J. De Groot, "Fire behavior in jack pine stands as related to the Canadian Forest Fire Weather Index System". Canadian Forest Service, Northern Forestry Centre, Edmonton, Alberta. Poster with text, 1988.

[15] P. M. Palheiro, P. Fernandes, and M. G. Cruz, "A fire behaviourbased fire danger classification for maritime pine stands: comparison of two approaches", in Fifth International Conference on Forest Fire Research, 2006, CD-ROM.

[16] N. P. Cheney, "Quantifying bushfires", Math. Comput. Model., vol. 13, pp. 9-15, 1990.

[17] V. Babrauskas, "Heat Release Rates", in The SFPE Handbook of Fire Protection Engineering, 3rd ed, M. A. Quincy, J. P. Di Nenno and W. D. Walton, Ed. National Fire Protection Association and The Society of Fire Protection Engineers, 2002, pp. 1-37.

[18] R. C. Rothermel, "A mathematical model for predicting fire spread in wildland fuels", USDA Forest Service, Research Paper, INT$115,1972$.

[19] W. Thornton, "The relation of oxygen to the heat of combustion of organic compounds", Philos. Mag. J. Sci., vol. 33, pp. 196-203, 1917.

[20] C. Huggett, "Estimation of the rate of heat release by means of oxygen consumption", J. Fire Flammability, vol. 12, pp. 61-65, 1980 .

[21] W. J. Parker, "Calculations of the heat release rate by oxygen consumption for various applications", NBSIR 81-2427-1, 1982.

[22] M. L. Janssens, "Measuring rate of heat release by oxygen consumption", Fire Technol., vol. 27, pp. 234-249, 1991.

[23] C. Moro, "Détermination des caractéristiques physiques de particules de quelques espèces forestières méditerranéennes", INRA PIF2006-06, 2006

[24] V. Babrauskas, "Effective heat of combustion for flaming combustion of conifers", Can. J. For. Res., vol. 36, pp. 659-663, 2006. 